\title{
Positive Surgical Margin
}

National Cancer Institute

\section{Source}

National Cancer Institute. Positive Surgical Margin. NCI Thesaurus. Code C48620.

Indicates the presence of tumor cells at the edge of a surgically excised specimen. 